\author{
Alain Cariou \\ Kjetil Sunde
}

\section{Cold fluids during cardiac arrest: faster cooling but not better outcome!}

Received: 20 October 2014

Accepted: 26 October 2014

Published online: 13 November 2014

(C) Springer-Verlag Berlin Heidelberg and ESICM 2014

\begin{abstract}
A. Cariou (汭)
Medical Intensive Care Unit, AP-HP, Cochin University Hospital, 27 rue du Faubourg Saint-Jacques, 75679 Paris Cedex 14, France e-mail: alain.cariou@cch.aphp.fr
\end{abstract}

\section{K. Sunde}

Surgical Intensive Care Unit Ullevål, Division of Emergencies and Critical Care, Department of Anaesthesiology, Oslo University Hospital, Oslo, Norway

In the current issue of Intensive Care Medicine, Debaty and coworkers report the results of a very innovative strategy aiming to decrease post-anoxic brain injury [1], which accounts for the vast majority of deaths in patients resuscitated from a cardiac arrest (CA) [2]. Anoxo-ischemic damages are mainly caused by a reperfusion injury called "post-cardiac arrest syndrome" responsible for a cascade of pathophysiological mechanisms that especially damage the brain [3]. This has stimulated intense research (experimental and clinical) over the last 30-40 years aiming to limit the worsening of these neurological lesions occurring during the post-CA period [3], which culminated 10 years ago with the publication of two randomized landmark trials demonstrating that therapeutic hypothermia $(\mathrm{TH})$ post-CA was an effective treatment in getting more neurologically intact survivors $[4,5]$. This led to a rapid change in international recommendations on the management of patients initially surviving CA [6]. Based on clinical evidence, the latest international guidelines recommend that most comatose adult patients with spontaneous circulation after out-of-hospital CA (OHCA) should be cooled to $32-34{ }^{\circ} \mathrm{C}$ for 12-24 h [7]. However, a recent very well performed randomized trial (the TTM trial) compared two levels of $\mathrm{TH}$, and found no differences in outcome between 33 and $36^{\circ} \mathrm{C}[8,9]$.

In routine practice, $\mathrm{TH}$ is initiated at hospital admission in the emergency department, angiographic laboratory or in the intensive care unit (ICU). Numerous experimental data suggested that a more aggressive approach consisting in a cooling performed as soon as possible after $\mathrm{CA}$ could be associated with a greater protective effect [10]. Accordingly, different strategies have been proposed to permit rapid cooling, and intravenous administration of ice-cold fluids is one option that has frequently been investigated in recent years, as this is a simple and easy method. In addition to the cooling effect, controlled in-hospital use of fluids in the early post-resuscitation period is probably important to stabilize the patients, considering the sepsis-like syndrome that is common in these patients [11]. However, in a recent large randomized trial, prehospital rapid infusion of up to $2 \mathrm{~L}$ of $4{ }^{\circ} \mathrm{C}$ normal saline induced mild hypothermia faster than standard care, but did not improve survival or neurological status at discharge after resuscitation from OHCA [12]. Importantly, the intervention was associated with significantly increased incidence of rearrest during transport, and also time spent in the prehospital setting and pulmonary edema with early diuretic use after admission. So clearly, uncontrolled use of large amounts of fluids in the prehospital setting does not seem to be recommended. 
Table 1 Risks and benefits of intra-arrest cooling with cold fluids

\begin{tabular}{ll}
\hline Benefits & Risks \\
\hline Maximal protective effects on brain and other tissues & Decrease in cerebral and coronary perfusion pressure \\
Myocardial infarct size reduction (if the cause of arrest) & Pulmonary edema and detrimental respiratory consequences \\
Early volume replacement & Overcooling \\
\hline
\end{tabular}

Many animal studies have also suggested that the benefit to neurological outcome could be further improved if TH is started during cardiopulmonary resuscitation (CPR), so-called intra-arrest cooling [13]. In a French study, Bruel et al. rapidly cooled 33 CA patients with ice-cold fluids during CPR, and they decreased the body temperature by $2.1^{\circ} \mathrm{C}$ after a median of $16 \mathrm{~min}$ after return of spontaneous circulation (ROSC) [14]. Considering this was a feasibility study without a control group, the results allowed the design of a larger, multicenter, randomized trial to assess whether prehospital induced cooling after OHCA confers neurological benefits. This led Debaty and coworkers to conduct a $1: 1$ randomized, multicenter study in three mobile ICUs and four critical care units in France, presented in this issue [1]. In addition to usual care, patients in the intervention group received an infusion of up to $2,000 \mathrm{~mL}$ of ice-cold $0.9 \%$ saline solution during OHCA [1]. As the aim of this study was to compare neurological damages following $\mathrm{CA}$, the authors chose the concentration of neuron-specific enolase (NSE), a marker of cerebral injury, at $24 \mathrm{~h}$ as primary endpoint, but clinical outcome was also assessed using cerebral performance scores. Intra-arrest cooling decreased the core temperature by an average of $1.7^{\circ} \mathrm{C}$ prior to hospital admission and shortened the time to reach $34{ }^{\circ} \mathrm{C}$ by an average of $93 \mathrm{~min}$ compared to inhospital TH alone. However, this was not associated with differences in markers of neurological injury or in neurological outcome.

Even if this study was well performed, the results are not surprising considering the low number of initial shockable rhythms in both groups (less than $30 \%$ ), the high number of initial asystole (approximately $65 \%$ ), more than a median $17 \mathrm{~min}$ from call to arrival of advanced life support (ALS), a median 27-30 min from collapse to ROSC and the resulting very low overall survival in both groups (16\% among those admitted with ROSC), indicating that the included patients were too severely injured and not at all comparable to the patients in the HACA trial [5] or the recent TTM trial [8]. This is also confirmed by the lower temperature on admission in the control group than in previous studies [15], higher
NSE values and a high heart rate on admission despite hypothermia [16], all factors associated with worse outcome. Even when started during CPR, TH can definitively not save brains that are already too damaged.

Furthermore the net effect of intra-arrest cooling with fluids also remains questionable for other reasons. Animal studies performed in the 1980s showed that fluid loading during resuscitation reduced both cardiac and cerebral blood flow, as a result of the increased right atrial and intracerebral pressures [17]. In 2009 Yannopoulos et al. [18] also showed that cold saline altered coronary perfusion pressure. All these findings suggest that intra-arrest cooling with large amounts of cold fluids might be more detrimental than beneficial during CPR (Table 1). If intraarrest cooling is to be further explored, other methods should probably be preferred. To date, several possibilities are in development. In a rabbit model of cardiac arrest, total liquid ventilation (TLV) with temperaturecontrolled perfluorocarbons has been shown to induce a very rapid and generalized cooling. This "ultrafast cooling" exerts potent neurological and cardiac protection and could be a relevant approach to provide a global and protective hypothermia against the post-cardiac arrest syndrome [19]. Another approach consists in using transnasal evaporative cooling, which has sufficient heat transfer capacity for effective intra-arrest cooling in animal models. This method allows cooling to be initiated within minutes of the arrest and has been shown to cool the brain before circulation is reestablished. In humans, the system has been tested in a randomized field study, which showed promising results regarding feasibility and effectiveness in accelerating the cooling process [20]. A multicenter, prospective study is currently recruiting to explore its ability to improve outcome (NCT01400373).

Finally, several questions remain unanswered: considering that $\mathrm{TH}$ or targeted temperature management is useful, what temperature should be targeted and when should it start? The complexity and specific pathophysiology of cardiac arrest with different degrees of reperfusion injury indicate that it is probably not a "one size fits all" strategy, making research on this group of patients even more challenging. 


\section{References}

1. Debaty G, Maignan M, Savary D et al (2014) Impact of intra-arrest therapeutic hypothermia in outcomes of prehospital cardiac arrest: a randomized controlled trial. Intensive Care Med. doi: 10.1007/s00134-014-3519-x

2. Lemiale V, Dumas F, Mongardon N et al (2013) Intensive care unit mortality after cardiac arrest: the relative contribution of shock and brain injury in a large cohort. Intensive Care Med 39:1972-1980

3. Nolan JP, Neumar RW, Adrie C et al (2008) Post-cardiac arrest syndrome: epidemiology, pathophysiology, treatment, and prognostication. A scientific statement from the International Liaison Committee on Resuscitation; the American Heart Association Emergency Cardiovascular Care Committee; the Council on Cardiovascular Surgery and Anesthesia; the Council on Cardiopulmonary, Perioperative, and Critical Care; the Council on Clinical Cardiology; the Council on Stroke. Resuscitation 79:350-379

4. Bernard SA, Gray TW, Buist MD, Jones BM, Silvester W, Gutteridge G, Smith K (2002) Treatment of comatose survivors of out-of-hospital cardiac arrest with induced hypothermia. N Engl J Med 346:557-563

5. Hypothermia after Cardiac Arrest Study Group (2002) Mild therapeutic hypothermia to improve the neurologic outcome after cardiac arrest. N Engl J Med 346:549-556

6. Nolan JP, Morley PT, Hoek TL, Hickey RW, Advancement Life support Task Force of the International Liaison Committee on Resuscitation (2003) Therapeutic hypothermia after cardiac arrest. An advisory statement by the Advancement Life support Task Force of the International Liaison Committee on Resuscitation. Resuscitation 57:231-235
7. Deakin CD, Nolan JP, Soar J, Sunde K, Koster RW, Smith GB, Perkins GD (2010) European Resuscitation Council guidelines for resuscitation 2010 section 4. Adult advanced life support. Resuscitation 81:1305-1352

8. Nielsen N, Wetterslev J, Cronberg T, TTM Trial Investigators et al (2013) Targeted temperature management at $33^{\circ} \mathrm{C}$ versus $36^{\circ} \mathrm{C}$ after cardiac arrest. N Engl J Med 369:2197-2206

9. Annborn M, Bro-Jeppesen J, Nielsen N, TTM-trial investigators et al (2014) The association of targeted temperature management at 33 and $36{ }^{\circ} \mathrm{C}$ with outcome in patients with moderate shock on admission after out-of-hospital cardiac arrest: a post hoc analysis of the target temperature management trial. Intensive Care Med 40:1210-1219

10. Kuboyama K, Safar P, Radovsky A, Tisherman SA, Stezoski SW, Alexander $\mathrm{H}$ (1993) Delay in cooling negates the beneficial effect of mild resuscitative cerebral hypothermia after cardiac arrest in dogs: a prospective, randomized study. Crit Care Med 21:1348-1358

11. Sunde K, Pytte M, Jacobsen D et al (2007) Implementation of a standardised treatment protocol for post resuscitation care after out-of-hospital cardiac arrest. Resuscitation 73:29-39

12. Kim F, Nichol G, Maynard C et al (2014) Effect of prehospital induction of mild hypothermia on survival and neurological status among adults with cardiac arrest: a randomized clinical trial. JAMA 311:45-52

13. Zhao D, Abella BS, Beiser DG et al (2008) Intra-arrest cooling with delayed reperfusion yields higher survival than earlier normothermic resuscitation in a mouse model of cardiac arrest. Resuscitation 77:242-249
14. Bruel C, Parienti JJ, Marie W et al (2008) Mild hypothermia during advanced life support: a preliminary study in out-of-hospital cardiac arrest. Crit Care 12:R31

15. Den Hartog AW, de Pont AC, Robillard LB, Binnekade JM, Schultz MJ, Horn J (2010) Spontaneous hypothermia on intensive care unit admission is a predictor of unfavorable neurological outcome in patients after resuscitation: an observational cohort study. Crit Care 14:R121

16. Stær-Jensen H, Sunde K, Olasveengen TM et al (2014) Bradycardia during therapeutic hypothermia is associated with good neurologic outcome in comatose survivors of out-of-hospital cardiac arrest. Crit Care Med 42:2401-2408

17. Ditchey RV, Lindenfeld J (1984) Potential adverse effects of volume loading on perfusion of vital organs during closed-chest resuscitation. Circulation 69:181-189

18. Yannopoulos D, Zviman M, Castro V, Kolandaivelu A, Ranjan R, Wilson RF, Halperin HR (2009) Intracardiopulmonary resuscitation hypothermia with and without volume loading in an ischemic model of cardiac arrest. Circulation 120:1426-1435

19. Darbera L, Chenoune M, Lidouren F et al (2014) Hypothermic liquid ventilation prevents early hemodynamic dysfunction and cardiovascular mortality after coronary artery occlusion complicated by cardiac arrest in rabbits. Crit Care Med 41:e457-e465

20. Castrén M, Nordberg P, Svensson L et al (2010) Intra-arrest transnasal evaporative cooling: a randomized, prehospital, multicenter study (PRINCE: pre-ROSC intranasal cooling effectiveness). Circulation 122:729-736 